\title{
Report from the International Society of Endocrinology
}

The Seventh International Congress took place in Quebec City, July 1 to 7, 1984, and was attended by 6,300 registrants. The Congress site proved adequate to the demands, and the superb organization and warm friendship of the Canadian hosts were enjoyed by all. All of us must congratulate Dr. Fernand Labrie, Chairman of the Local Organizing Committee, and his many colleagues for their hard work and success. In addition to the Congress, there were 18 Satellite Symposia organized for the weeks just before and after the Congress. Thus, there was a rich experience in endocrinology for those who attended. The Central Committee of the ISE selected Kyoto, Japan as the site of the 1988 Congress. It will be held in July. Professor Hiroo Imura will be the Chairman of the Local Organizing Committee. His address is:

Professor Hiroo Imura, Department of Medicine, Kyoto University School of Medicine, 53 Kawahara-Cho Syogoin, Sakyo-Ku, Kyoto 606 (Japan)

The Central Committee elected Dr. Ernst Knobil, President, and Dr. Lesley Rees, Secretary-General. The new Chairman of the Executive Committee is Dr. Luciano Martini. Their addresses are, respectively:

Dr. Ernst Knobil,

University of Texas Medical School,

6431 Fannin Street,

P.O. Box 20708,

Houston, TX 77025 (USA)

Dr. Lesley H. Rees, St. Bartholomew’s Hospital, Bartholomew Close, London EC1A 7BE (England)

Dr. Luciano Martini, Direttore, Istituto di Endocrinnologia, Università di Milano, Via A, del Sarto, 21, 1-20129 Milano (Italy)

Other members of the Executive Committee are: Dr. A. Zarate - Mexico, Dr. M. Grumbach - USA, Dr. F. Labrie - Canada, Dr. R. Hoffenberg - UK, Dr. B. Halasz -Hungary.

The ISE for the first time awarded \$100,000 in travel grants to young endocrinologists or to endocrinologists from developing countries. It is almost certain that awards will be made again for the 1988 Congress. 